\title{
Mycoflora and Natural Incidence of Selected Mycotoxins in Rabbit and Chinchilla Feeds
}

\author{
Mariana Vanesa Greco, ${ }^{1,2}$ Alejandro Guillermo Pardo, ${ }^{1,2}$ Vanesa Ludemann, ${ }^{1}$ \\ Pablo Eduardo Martino, ${ }^{3,4}$ and Graciela Noemí Pose ${ }^{1,2,5}$ \\ ${ }^{1}$ Departamento de Ciencia y Tecnología, Universidad Nacional de Quilmes (UNQ), Roque Sáenz Peña 352, \\ B1876BXD Bernal, Provincia de Buenos Aires, Argentina \\ ${ }^{2}$ Consejo Nacional de Investigaciones Científicas y Técnicas (CONICET), Avenida Rivadavia 1917, C1033AAJ CABA, Argentina \\ ${ }^{3}$ Facultad de Ciencias Veterinarias, Universidad Nacional de la Plata, Calle 60 y 118 S/N, 1900 La plata, Buenos Aires, Argentina \\ ${ }^{4}$ Comisión de Investigaciones Científicas de la Provincia de Buenos Aires (CIC), Calle 526 entre 10 y 11, 1900 La Plata, \\ Buenos Aires, Argentina \\ ${ }^{5}$ Universidad Nacional de Río Negro, Mitre 331, 8336 Villa Regina, Río Negro, Argentina
}

Correspondence should be addressed to Graciela Noemí Pose, npose@unq.edu.ar

Received 3 November 2011; Accepted 29 December 2011

Academic Editor: Dongsheng Zhou

Copyright (C) 2012 Mariana Vanesa Greco et al. This is an open access article distributed under the Creative Commons Attribution License, which permits unrestricted use, distribution, and reproduction in any medium, provided the original work is properly cited.

\begin{abstract}
Mycotoxins are secondary metabolites produced by filamentous fungi that cause a toxic response when ingested by animals or man. Demand of natural fur, such as those from rabbit and chinchilla, produced under controlled conditions, has increased worldwide. The toxicogenic mycoflora contaminating feeds for these animals was enumerated and identified. Six of the major mycotoxins implicated in animal mycotoxicosis were detected and quantified. Moulds count ranged from $<10$ to $4.7 \times 10^{5} \mathrm{CFU} \mathrm{\textrm {g } ^ { - 1 }} ; 14 \%$ of the samples exceeded the limit that determines hygienic feed quality. More than twenty species belonging to the five most important mycotoxigenic mould genera were recovered. Among the analyzed mycotoxins, aflatoxins were recovered in $100 \%$ of the examined samples, deoxynivalenol in $95 \%$, fumonisins in $100 \%$, ochratoxin A in $98 \%$, T2 toxin in $98 \%$, and zearalenone in $100 \%$. Cooccurrence of mycotoxins was observed in $100 \%$ of the samples analyzed. Exposure to multiple mycotoxins was thus demonstrated for these animals.
\end{abstract}

\section{Introduction}

There is an increasing worldwide demand of natural fur produced under controlled conditions. Among them, chinchilla, fox, mink, and otter fur are quite appreciated. On the other hand, rabbit breeding besides fur provides meat intended for human consumption [1]. Worldwide production of rabbit meat was 1.1 million tons per year between 2002 and 2005 and has grown around $49 \%$ over the last 15 years with China, Italy, Spain, and France being the main producers [2]. In America, Argentina is the main producer and exporter. In 2004 Argentina exported 1400 tons of rabbit meat to the EU [2].

Commercial feedstuffs are the main consumables in rabbit and chinchilla breeding representing $60-70 \%$ of production cost [3]. Filamentous fungi are ubiquitous in nature and responsible for producing mycotoxins in agricultural crops [4]. Rabbit and chinchilla feed ingredients that constitute complete feed products are derived from different raw materials. Inadequate management of raw materials can lead to undesirable growth of fungi, leading to loss of nutritive substances and resulting in contamination by mycotoxins [5]. Lowered production, illness, and death can be consequences of mycotoxin-contaminated feeds [6].

One of the main features of mycotoxicosis in rabbits is feeding reduction (about 20-60\%) which causes a delay in growth and thus reduced productivity. Mycotoxicosis in rabbits includes acute or chronic pathologies depending on the mycotoxin involved, its concentration, period of exposure, accumulative effects, and synergisms among mycotoxins. In some cases abortion and death of adults may occur [7]. Also, it is necessary to consider that even though there 
TABle 1: Fungal counts $\left(\mathrm{CFU} \mathrm{g}^{-1}\right)$ from chinchilla and rabbit feed samples.

\begin{tabular}{lccc}
\hline Parameters & DRBC & DG18 & DCPA \\
\hline $\begin{array}{l}\text { No. of samples } \\
\text { tested }\end{array}$ & 42 & 42 & 42 \\
$\begin{array}{l}\text { Less count } \\
\left(\mathrm{CFU} \mathrm{g}^{-1}\right)\end{array}$ & $<10$ & $<10$ & $<10$ \\
$\begin{array}{l}\text { Highest count } \\
\left(\mathrm{CFU} \mathrm{g}^{-1}\right)\end{array}$ & $4.7 \times 10^{5}$ & $8.5 \times 10^{5}$ & $2.7 \times 10^{5}$ \\
$\begin{array}{l}\text { Average count } \\
\left(\mathrm{CFU} \mathrm{g}^{-1}\right)\end{array}$ & $3.34 \times 10^{4}$ & $7.34 \times 10^{4}$ & $3.02 \times 10^{4}$ \\
$\begin{array}{l}\text { Median count } \\
\left(\mathrm{CFU} \mathrm{g}^{-1}\right)\end{array}$ & $5 \times 10^{2}$ & $1.35 \times 10^{3}$ & $8 \times 10^{2}$ \\
$\begin{array}{l}\text { No. of samples } \\
\text { exceeding the limit } \\
\text { of hygienic quality }\end{array}$ & $6(17 \%)$ & $12(33 \%)$ & $7(19 \%)$ \\
\hline
\end{tabular}

TABLE 2: Fungal genus present in chinchilla and rabbit feed samples.

\begin{tabular}{lccc}
\hline Genus & $\begin{array}{c}\text { Number of } \\
\text { isolates }\end{array}$ & Fr $(\%)^{*}$ & $\mathrm{Rd}(\%)^{* *}$ \\
\hline Eurotium & 30 & 71.43 & 20 \\
Aspergillus & 21 & 50 & 14 \\
Cladosporium & 21 & 50 & 14 \\
Penicillium & 14 & 33.3 & 9.5 \\
Mucor & 14 & 33.3 & 9.5 \\
Paecilomyces & 4 & 9.5 & 2.7 \\
Fusarium & 3 & 7.1 & 2.1 \\
Trichoderma & 3 & 7.1 & 2.1 \\
Scopulariopsis & 3 & 7.1 & 2.1 \\
Alternaria & 1 & 2.4 & 0.7 \\
Others & 16 & 38 & 11 \\
Yeast & 18 & 42.9 & 12 \\
\hline
\end{tabular}

* Isolation frequency.

** Isolation relative density.

is little information available regarding the prevalence and concentration of mycotoxins in foods of animal origin, some toxins ingested by animals may be found in meat, milk, or eggs [8]. Regular monitoring of toxigenic mycoflora of the agriculturally based feeds and foods is an essential prerequisite for development of strategies to control or prevent mycotoxin exposure of animal and human populations [9].

Despite the great attention that has been paid to the study of toxicogenic moulds and their mycotoxins in various feeds, little is known about fungal and mycotoxin contamination of mixed chinchilla and rabbit feed. Thus, the aim of this work was to study the toxicogenic mycoflora including enumeration and identification of mould genera and species naturally contaminating feeds for these animals along with detection and quantification of the major mycotoxins: aflatoxins, ochratoxin A, T-2 toxin, fumonisins, deoxynivalenol $(\mathrm{DON})$, and zearalenone.
TABle 3: Fungal species present in chinchilla and rabbit feed samples.

\begin{tabular}{|c|c|c|c|}
\hline Species & $\begin{array}{c}\text { Number of } \\
\text { isolates }\end{array}$ & $\operatorname{Fr}(\%)^{*}$ & $\operatorname{Rd}(\%)^{* *}$ \\
\hline Eurotium amstelodami & 21 & 50.00 & 15.44 \\
\hline E. chevalieri & 11 & 26.19 & 8.09 \\
\hline E. repens & 13 & 30.95 & 9.56 \\
\hline E. rubrum & 8 & 19.05 & 5.88 \\
\hline Eurotium sp. & 7 & 16.67 & 5.15 \\
\hline Aspergillus candidus & 2 & 4.76 & 1.47 \\
\hline A. flavipes & 2 & 4.76 & 1.47 \\
\hline A. flavus & 3 & 7.14 & 2.21 \\
\hline A. niger & 1 & 2.38 & 0.74 \\
\hline A. parasiticus & 2 & 4.76 & 1.47 \\
\hline A. penicillioides & 2 & 4.76 & 1.47 \\
\hline A. terreus & 1 & 2.38 & 0.74 \\
\hline A. versicolor & 2 & 4.76 & 1.47 \\
\hline Aspergillus sp. & 9 & 21.43 & 6.62 \\
\hline $\begin{array}{l}\text { Cladosporium } \\
\text { cladosporioides }\end{array}$ & 21 & 50.00 & 15.44 \\
\hline $\begin{array}{l}\text { Penicillium } \\
\text { brevicompactum }\end{array}$ & 2 & 4.76 & 1.47 \\
\hline P. expansum & 8 & 19.05 & 5.88 \\
\hline P. funiculosum & 1 & 2.38 & 0.74 \\
\hline P. olsonii & 1 & 2.38 & 0.74 \\
\hline P. roquefort $i$ & 1 & 2.38 & 0.74 \\
\hline Penicillium sp. & 2 & 4.76 & 1.47 \\
\hline Fusarium proliferatum & 3 & 7.14 & 2.21 \\
\hline F. subglutinans & 1 & 2.38 & 0.74 \\
\hline Alternaria tenuissima & 1 & 2.38 & 0.74 \\
\hline Paecilomyces variotii & 4 & 9.52 & 2.94 \\
\hline Scopulariopsis brevicaulis & 3 & 7.14 & 2.21 \\
\hline Trichoderma harzianum & 3 & 7.14 & 2.21 \\
\hline Mucor sp. & 1 & 2.38 & 0.74 \\
\hline
\end{tabular}

* Isolation frequency.

${ }^{* *}$ Isolation relative density.

\section{Materials and Methods}

2.1. Sample Collection and Preparation. A total of 42 representative samples (1-2 kg per sample) of finished rabbit (17) and chinchilla (25) feeds were collected from 7 companies in 5 provinces of Argentina (Buenos Aires, Córdoba, La Pampa, La Rioja, and Mendoza) in 2010. All samples were homogenized and divided to obtain a $1 \mathrm{~kg}$ working sample for analysis. Each sample was ground in a laboratory mill. For mycological examination feed samples were immediately analyzed upon arrival or they were stored for 2-3 days in paper bags at room temperature (about $25^{\circ} \mathrm{C}$ ). Feed samples intended for mycotoxin analysis were stored at $-20^{\circ} \mathrm{C}$.

2.2. Mycological Analysis. The dilute plate technique was used for enumeration and isolation of fungi [11]. Ten grams of each milled feed sample was mixed with $90 \mathrm{~mL}$ of $0.1 \%$ 
TABLE 4: Number of samples tested, number of positive samples, and percentage and levels of detected mycotoxins.

\begin{tabular}{lcccccc}
\hline \multirow{2}{*}{ Parameter } & & \multicolumn{4}{c}{ Mycotoxins (ppb) } \\
& Aflatoxins & Deoxynivalenol & Fumonisins & Ochratoxin A & T2 toxin & Zearalenone \\
\hline No. of samples tested & 42 & 42 & 42 & 42 & 42 & 42 \\
No. of positive samples & 42 & 40 & 42 & 41 & 41 & $98 \%$ \\
Percentage positive (\%) & $100 \%$ & $95 \%$ & $100 \%$ & $98 \%$ & $<0$ \\
Range (ppb) & $<1.70-22.55$ & $222-1740$ & $222-6000$ & $<5-26.57$ & $<50-129.88$ & $<50-177.97$ \\
Median (ppb) & 7.26 & 743 & 462 & 9.74 & 50 & 50 \\
Highest level (ppb) & 22.55 & 1740 & 6000 & 26.57 & 129.88 & 177.97 \\
\hline
\end{tabular}

peptone and shaken on a horizontal shaker for 20 minutes. Then, $0.1 \mathrm{~mL}$ of a proper spore suspension dilution (made up to $10^{5}$ spores per $\mathrm{mL}$ ) was inoculated onto the following media: dichloran rose bengal chloramphenicol agar (DRBC) to enumerate total culturable fungi, dichloran $18 \%$ glycerol agar (DG18) to enumerate xerophilic fungi, and dichloran chloramphenicol peptone agar (DCPA) for selective isolation of Alternaria and Fusarium species [11]. Plates were incubated at $25^{\circ} \mathrm{C}$ for 7 days. The DCPA plates were incubated under a $12 \mathrm{~h}$ of light: $12 \mathrm{~h}$ of darkness photoperiod. For counting, plates containing 10-100 colonies were used and the results were expressed as colony-forming units per gram of sample $\left(\mathrm{CFU} \mathrm{g}^{-1}\right)$ [11]. Individual $\mathrm{CFU} \mathrm{g}^{-1}$ counts for each colony type, considered to be different, were recorded. Representative colonies of each type were transferred for subculturing onto plates with malt extract agar (MEA) or water agar (WT), for moulds suspected to belong to Alternaria or Fusarium genera. Filamentous fungi were identified at genus level according to macro- and microscopic criteria in accordance with Samson et al. [12]. Fungal isolates were identified at species level according to the leading authorities: Penicillium and Aspergillus spp. according to Pitt and Hocking [11], Fusarium spp. according to Nelson et al. [13], Alternaria spp. according to Simmons [14], and other fungi according to Pitt and Hocking [11]. The isolation frequency $(\mathrm{Fr})$ and relative density (RD) of genus/species were calculated according to González et al. [15], Pacin et al. [16], and Saleemi et al. [9] as follows:

$\operatorname{Fr}(\%)=$ number of samples with a genus or species/total number of samples $\times 100$.

$\mathrm{RD}(\%)=$ number of isolates of a genus or species/total number of fungi isolated $\times 100$.

All the isolates were preserved on agar slants of malt extract agar (MEA) or potato dextrose agar (PDA) for Alternaria and Fusarium at $4^{\circ} \mathrm{C}$ and cryopreserved in $18 \%$ glycerol at $-20^{\circ} \mathrm{C}$.

2.3. Mycotoxin Analysis. To evaluate mycotoxin occurrence, feed samples were subjected to quantitative analyses using ELISA-based analytical test kits for aflatoxins, ochratoxin A, T-2 toxin, fumonisins, deoxynivalenol (DON), and zearalenone (RIDASCREEN FAST, R-Biopharm AG). The extraction procedures were according to manufacturer protocols. In brief, $5 \mathrm{~g}$ of ground sample was extracted with $25 \mathrm{~mL}$ of $70 \%$ methanol for aflatoxins, T-2 toxin, zearalenone, and fumonisins. For ochratoxin A and DON, samples were extracted with $12.5 \mathrm{~mL}$ of $70 \%$ methanol or $100 \mathrm{~mL}$ of distilled water, respectively. Afterwards, samples were shaken vigorously for 3 minutes and the extracts filtered through the Whatman $\mathrm{N}^{\circ} 1$ paper. Then, aflatoxin, ochratoxin $\mathrm{A}$, $\mathrm{T}$ 2 toxin, and zearalenone filtrates were diluted with distilled water in the ratio $1: 1$ and fumonisin filtrates in the ratio $1: 14$. Fifty $\mu \mathrm{L}$ of the diluted filtrate per well were used for testing.

\section{Results}

This study shows that fungi and mycotoxins were present in all the feed samples assayed. Fungal counts $\left(\mathrm{CFU} \mathrm{g}{ }^{-1}\right)$ on each medium are shown in Table 1. Total fungal counts on DRBC ranged from $<10$ to $4.7 \times 10^{5} \mathrm{CFU} \mathrm{g}^{-1}$. High fungal contamination was found in 6 out of 42 samples, exceeding the limit of $1 \times 10^{4} \mathrm{CFU} \mathrm{g}^{-1}$, that determines feed hygienic quality [17]. Xerophile moulds counts ranged from $<10$ to $8.5 \times 10^{5} \mathrm{CFU} \mathrm{g}^{-1}$. Spoilage of feedstuff can be due to xerophilic fungi, which are capable of rapid growth above about $0.77 \mathrm{a}_{w}$ and of slow growth at $0.75 \mathrm{a}_{w}$ and below, down to about $0.68 \mathrm{a}_{w}$ [11]. On DCPA fungal counts ranged from $<10$ to $2.7 \times 10^{5} \mathrm{CFU} \mathrm{g}^{-1}$.

Both field and storage fungi were found in this study. Mycotoxigenic genera such as Aspergillus, Penicillium, Fusarium, and Alternaria were recorded. These moulds are of great importance due to potential mycotoxin production, which can contaminate many agricultural commodities like wheat, oat, barley, sunflower, soybean, and so forth, used in the formulation of finished feeds. Cladosporium, Trichoderma, and other mitosporic Ascomycetes were also found. One genus belonging to mycotoxigenic Ascomycetes, Eurotium, and one genus belonging to Zygomycetes, Mucor, were determined. The most frequent fungi were those from the genus Eurotium, recovered from 29 samples ( $\mathrm{Fr} 69 \%$ ). In the second place were moulds from the genus Aspergillus, recovered from 22 samples ( $\operatorname{Fr} 52.4 \%$ ). moulds from the genus Cladosporium ( $\mathrm{Fr} 42.5 \%$ ), Penicillium (Fr 33.3\%), and Mucor (Fr 33.3\%) and yeast (Fr 40.5\%) were recovered with relative high frequency. In less proportion, other genera recovered were Fusarium, Alternaria, Trichoderma, Scopulariopsis, and Paecilomyces (Table 2).

The fungal species isolated on different agar media are shown in Table 3. This table also illustrates the frequency 
TABLE 5: Concentration of different mycotoxins in chinchilla and rabbit feed samples. ND: not detected; CH: chinchilla; R: rabbit.

\begin{tabular}{|c|c|c|c|c|c|c|}
\hline \multicolumn{7}{|c|}{ Mycotoxins (ppb) } \\
\hline Samples tested & Aflatoxins & Deoxynivalenol & Fumonisins & Ochratoxin A & T2 toxin & Zearalenone \\
\hline $\mathrm{CH} 1$ & 3.91 & 393 & 222 & 5 & 50 & 50 \\
\hline $\mathrm{CH} 2$ & 1.84 & ND & 222 & 8.09 & 50 & 50 \\
\hline $\mathrm{CH} 3$ & 1.7 & ND & 222 & 9.74 & ND & 50 \\
\hline $\mathrm{CH} 4$ & 6 & 737 & 222 & 7.77 & 50 & 50 \\
\hline $\mathrm{CH} 5$ & 6.08 & 761 & 331 & 7.83 & 50 & 50 \\
\hline CH6 & 7.22 & 1592 & 222 & 6.24 & 50 & 50 \\
\hline $\mathrm{CH} 7$ & 7.19 & 222 & 270 & 6.53 & 50 & 50 \\
\hline $\mathrm{CH} 8$ & 5.73 & 610 & 795 & 12.48 & 50 & 50 \\
\hline $\mathrm{CH} 9$ & 5.55 & 1080 & 598 & 10.17 & 50 & 80.17 \\
\hline $\mathrm{CH} 10$ & 4.26 & 1210 & 370 & 8.95 & 50 & 50 \\
\hline $\mathrm{CH} 11$ & 6.24 & 868 & 525 & 8.66 & 50 & 50 \\
\hline $\mathrm{CH} 12$ & 7.64 & 629 & 732 & 8.6 & 50 & 50 \\
\hline $\mathrm{CH} 13$ & 8.6 & 488 & 503 & 13.19 & 50 & 50 \\
\hline CH14 & 8.77 & 409 & 370 & 10.23 & 50 & 50 \\
\hline CH15 & 9.24 & 760 & 866 & 23.49 & 50 & 82.12 \\
\hline $\mathrm{CH} 16$ & 7.09 & 1210 & 222 & 23.49 & 50 & 68.69 \\
\hline CH17 & 6.92 & 1300 & 222 & 15.25 & 50 & 75.59 \\
\hline CH18 & 7.5 & 548 & 626 & 12.63 & 50 & 53.96 \\
\hline CH19 & 8.77 & 937 & 1030 & 11.81 & 50 & 50 \\
\hline $\mathrm{CH} 20$ & 8.24 & 798 & 715 & 23.34 & 50 & 50 \\
\hline $\mathrm{CH} 21$ & 10.17 & 1720 & 222 & 25.38 & 50 & 58.34 \\
\hline $\mathrm{CH} 22$ & 9.46 & 241 & 447 & 11.59 & 50 & 66.49 \\
\hline $\mathrm{CH} 23$ & 6.67 & 1390 & 975 & 16.91 & 50 & 79.9 \\
\hline $\mathrm{CH} 24$ & 10.98 & 1660 & 498 & 11.59 & 50 & 78.81 \\
\hline $\mathrm{CH} 25$ & 9.15 & 462 & 340 & 10.9 & 50 & 71.2 \\
\hline R1 & 22.55 & 327 & 6000 & 5 & 50 & 50 \\
\hline $\mathrm{R} 2$ & 3.66 & 222 & 236 & ND & 81.75 & 50 \\
\hline R3 & 1.7 & 355 & 222 & 5 & 50 & 50 \\
\hline $\mathrm{R} 4$ & 1.99 & 279 & 222 & 5 & 50 & 50 \\
\hline R5 & 7.2 & 222 & 3110 & 6.6 & 50 & 50 \\
\hline R6 & 5.57 & 256 & 1500 & 5.76 & 50 & 50 \\
\hline R7 & 7.46 & 222 & 376 & 5.55 & 50 & 50 \\
\hline $\mathrm{R} 8$ & 9.72 & 916 & 562 & 5 & 50 & 50 \\
\hline R9 & 9.93 & 1300 & 953 & 17.44 & 50 & 50 \\
\hline R10 & 9.97 & 1100 & 581 & 26.57 & 50 & 50 \\
\hline R11 & 7.96 & 700 & 709 & 8.43 & 129.88 & 50 \\
\hline R12 & 6.14 & 1190 & 477 & 8.54 & 120.27 & 50 \\
\hline R13 & 7.14 & 749 & 241 & 16.81 & 128.98 & 50 \\
\hline R14 & 9.6 & 222 & 786 & 12.18 & 50 & 177.97 \\
\hline R15 & 7.94 & 1740 & 311 & 13.11 & 50 & 140.38 \\
\hline R16 & 9.19 & 1690 & 390 & 9.54 & 50 & 105.36 \\
\hline R17 & 7.29 & 467 & 492 & 7.01 & 50 & 50 \\
\hline
\end{tabular}

and relative density of recovered species. Among Eurotium species, E. amstelodami was the most prevalent (Fr 50\%). Other Eurotium spp. recovered were E. chevalieri, E. repens, and E. rubrum. Mycotoxigenic species such as A. flavus, $A$. parasiticus, $P$. expansum, $P$. roqueforti, F. proliferatum, and F. subglutinans were also found in our work.

There is only limited data on the occurrence of important mycotoxins in rabbit feed; thus, research and surveys in this 
TABLE 6: Recommended maximum concentration of mycotoxins in rabbit feed [10].

\begin{tabular}{lcc}
\hline Mycotoxin & $\begin{array}{c}\text { Maximum content for feed with a moisture } \\
\text { content of } 12 \%\end{array}$ \\
& ppm $(\mathrm{mg} / \mathrm{kg})$ & $\mathrm{ppb}(\mu \mathrm{g} / \mathrm{kg})$ \\
\hline Aflatoxin B1 & 0.02 & 20 \\
Ochratoxin A & 5 & 5000 \\
Deoxynivalenol & 5 & 5000 \\
Zearalenone & 0.50 & 500 \\
Fumonisin B1 + B2 & 5 & 5000 \\
\hline
\end{tabular}

area are very important [10]. In our study we have determined that all samples were contaminated with mycotoxins (Table 4). The concentration of different mycotoxins in finished mixed chinchilla and rabbit feed samples is shown in Table 5. Recommended maximum amount of mycotoxins in rabbit feed is shown in Table 6 [10]. Though only one sample had aflatoxin and fumonisin concentrations exceeding the recommended limits, several toxins have been detected in low concentrations in all the samples, which might lead to a response of synergic toxicity in animals under this type of exposure (Table 5).

\section{Discussion}

Fungal growth on raw materials used as ingredients (in the field or during silage storage) leads to contamination of the final feed. This fungal growth reduces nutritional value and may result in the production of mycotoxins, which constitute a risk factor for animal health $[5,18]$. Mycotoxigenic fungi, such as those we found in our work, are undesirable because of their potential for mycotoxin production. Other fungi isolated such as Mucor and Cladosporium species may cause mycotic abortion and allergy in animals and humans [19].

The genus Eurotium is an important mycotoxin producer. Eurotium species can produce echinulin, neoechinulin A, flavoglaucin, physcion, auroglaucin, dihydroauroglaucin, and tetrahydroauroglaucin [20]. Echinulin has been detected in feeds containing a high propagule density of $E$. chevalieri and $E$. amstelodami. These species were capable of producing echinulin on rice [21]. Rabbits injected intraperitoneally with purified echinulin have shown a significant degree of lung and liver damage [22]. Also, the production of aflatoxins has been reported for E. amstelodami, E. repens, and E. rubrum [23-26], and the production of ochratoxin A has been reported for E. amstelodami [23]. However, we should bear in mind that rabbits are one of the most sensitive animals to toxins such as aflatoxins, zearalenone, fumonisins, DON, and T-2 toxin. Aflatoxicosis in rabbits has been reported with $33-10400 \mathrm{ppb}$ of aflatoxin B1 in feed. The rabbits affected showed loss of coordination, loss of weight, and jaundice before death. Also, zearalenone affects viability of embryos and fertility. The consumption of feed contaminated with $200 \mathrm{ppb}$ zearalenone produced abortion and yellow diarrhea in suckling rabbits. Furthermore, fumonisin B1 can cause multiorgan failure (i.e., kidneys, liver, lungs, heart, brain), leukoencephalomalacia, and reduction in the fetus weight [27]. Also, T-2 toxin is hepato- and nephrotoxic in rabbits affecting reproduction as well as the digestive and respiratory systems [27]. Producers have usually been concerned with death due to diarrhea in rabbits. The DON levels of commercial feeds, particularly those containing more than $1000 \mathrm{ppb}$ DON, have been blamed by some rabbit producers for this problem [10]. In our work we have shown that 13 out of 42 samples (31\%) had levels of DON between 1080 and $1720 \mathrm{ppb}$.

Although the scientific literature offers a broad variety of information about the effects of individual mycotoxins on various animal species, concurrent exposure to multiple mycotoxins is more likely in the livestock industry. Poor livestock performance and/or disease symptoms may be due to the synergistic interactions between multiple mycotoxins [28]. In our work, cooccurrence of mycotoxins was demonstrated in $100 \%$ of the samples assayed (Tables 4 and 5). In Argentina, there is rather limited information concerning natural occurrence of mycotoxins in feedstuff, particularly with respect to rabbit feed. Only one work reported that $25 \%$ of rabbit feed samples from Córdoba province were contaminated with ochratoxin A with a mean level of $21.8 \mathrm{ppb}$ [29]. Also there is scarce information from other parts of the world. Mohanamba et al. [30] reported that $77 \%$ of rabbit feed samples were contaminated with aflatoxins in India.

\section{Conclusions}

The present study has provided information about the contaminating toxigenic mycoflora in rabbit and chinchilla feeds in Argentina. This is the first report describing the cooccurrence of six mycotoxins. These toxic substances are known to be either carcinogenic, neurotoxic, nephrotoxic, dermatotoxic, or immunosuppressive. Although the synergic effects of mycotoxins on health and productivity of other animal species such as poultry have been well documented [31], more studies are needed in order to screen the presence of different mycotoxins in different feeds. Particular attention should be paid to the cooccurrence and synergic effects of mycotoxins present in low levels in order to avoid the consumption of contaminated feeds which could provoke acute or chronic illnesses leading to economic losses.

\section{Acknowledgments}

This work was supported by grants from the CONICET-PIP and FONCYT-PICT JI.

\section{References}

[1] A. Losada, "Pieles de conejo de criadero controlado," in Cabaña Lagunita, 2006, http://www.criadeconejos.com.ar/html/ pielesconejos.html.

[2] D. Quintans, "Análisis económico de la actividad cunícola para producción de carne," in Ministerio de Ganadería, Agricultura y Pesca del Uruguay, 2007, http://www.mgap.gub.uy/opypa/ANUARIOS/Anuario07/docs/38_Proy_Estus_Docs_Caratula.pdf. 
[3] E. Maggi, "Carne de conejos: Análisis de Cadena Alimentaria," in Secretaría de Agricultura, Ganadería, Pesca y Alimentos (SAGPYA), Ministerio de Economía y Producción, Argentina, 2006.

[4] A. Venancio and R. Paterson, "The challenge of mycotoxins," in Food Safety - A Practical and Case Study Approach, A. McElhatton and R. J. Marshall, Eds., pp. 24-47, Springer, Berlin, Germany, 2007.

[5] L. R. Cavaglieri, K. M. Keller, C. M. Pereyra et al., "Fungi and natural incidence of selected mycotoxins in barley rootlets," Journal of Stored Products Research, vol. 45, no. 3, pp. 147-150, 2009.

[6] J. Robens and K. Cardwell, "The costs of mycotoxin management in the United States," in Aflatoxin and Food Safety, H. K. Abbas, Ed., pp. 1-12, CRC Press, Boca Raton, Fla, USA, 2005.

[7] A. Gimeno and M. L. Martins, Micotoxinas y Micotoxicosis en Animales y Humanos, Special Nutrients, Miami, Fla, USA, 1st edition, 2007.

[8] P. T. Mngadi, R. Govinden, and B. Odhav, "Co-occurring mycotoxins in animal feeds," African Journal of Biotechnology, vol. 7, no. 13, pp. 2239-2243, 2008.

[9] M. K. Saleemi, M. Z. Khan, A. Khan, and I. Javed, "Mycoflora of poultry feeds and mycotoxins producing potential of Aspergillus species," Pakistan Journal of Botany, vol. 42, no. 1, pp. 427-434, 2010.

[10] M. Mézes and K. Balogh, "Mycotoxins in rabbit feed: a review," World Rabbit Science, vol. 17, no. 2, pp. 53-62, 2009.

[11] J. Pitt and A. Hocking, Fungi and Food Spoilage, Springer, Berlin, Germany, 3rd edition, 2009.

[12] R. A. Samson, E. S. Hoekstra, and J. C. Frisvad, Introduction to Food and Airborne Fungi, Centraalbureau voor Schimmelcultures, Utrecht, The Netherlands, 7th edition, 2004.

[13] P. Nelson, T. Toussoun, and W. Marasas, Fusarium species: An Illustrated Manual for Identification, Pennsylvania State University Press, University Park, Tex, USA, 1983.

[14] E. Simmons, Alternaria: An Identification Manual, American Society of Microbiology, Washington, DC, USA, 1st edition, 2009.

[15] H. H. L. González, S. L. Resnik, R. T. Boca, and W. F. O. Marasas, "Mycoflora of Argentinian corn harvested in the main production area in 1990," Mycopathologia, vol. 130, no. 1, pp. 29-36, 1995.

[16] A. M. Pacin, H. H. L. González, M. Etcheverry, S. L. Resnik, L. Vivas, and S. Espin, "Fungi associated with food and feed commodities from Ecuador," Mycopathologia, vol. 156, no. 2, pp. 87-92, 2003.

[17] Good Manufacture Practices (GMP), "Regulations on product standards in the animal feed sector," GMP14, 2005.

[18] D. Garon, E. Richard, L. Sage, V. Bouchart, D. Pottier, and P. Lebailly, "Mycoflora and multimycotoxin detection in corn silage: experimental study," Journal of Agricultural and Food Chemistry, vol. 54, no. 9, pp. 3479-3484, 2006.

[19] A. R. Khosravi, M. Dakhili, and H. Shokri, "A mycological survey on feed ingredients and mixed animal feeds in Ghom province, Iran," Pakistan Journal of Nutrition, vol. 7, no. 1, pp. 31-34, 2008.

[20] L. Butinar, P. Zalar, J. C. Frisvad, and N. Gunde-Cimerman, "The genus Eurotium - members of indigenous fungal community in hypersaline waters of salterns," FEMS Microbiology Ecology, vol. 51, no. 2, pp. 155-166, 2005.

[21] R. F. Vesonder, R. Lambert, D. T. Wicklow, and M. L. Biehl, "Eurotium spp. and echinulin in feed refused by swine," Applied and Environmental Microbiology, vol. 54, no. 3, pp. 830831, 1988.
[22] M. Ali, N. Mohammed, M. A. Alnaqeeb, R. A. Hassan, and H. S. Ahmad, "Toxicity of echinulin from Aspergillus chevalieri in rabbits," Toxicology Letters, vol. 48, no. 3, pp. 235-241, 1989.

[23] M. L. Abarca, M. R. Bragulat, G. Castellá, F. Accensi, and F. J. Cabañes, "Hongos productores de micotoxinas emergentes," Revista Iberoamericana de Micología, vol. 17, no. 2, pp. S63S68, 2000.

[24] M. M. Kulik and C. E. Holaday, "Aflatoxin: a metabolic product of several fungi," Mycopathology and Mycology Applied, vol. 30, no. 2, pp. 137-140, 1966.

[25] J. Leitao, G. de Saint-Blanquat, and J. R. Bailly, "Action of phosphine on production of aflatoxins by various Aspergillus strains isolated from foodstuffs," Applied and Environmental Microbiology, vol. 53, no. 10, pp. 2328-2331, 1987.

[26] J. Leitao, J. Le Bars, and J. R. Bailly, "Production of aflatoxin B1 by Aspergillus ruber Thom and Church," Mycopathologia, vol. 108, no. 2, pp. 135-138, 1989.

[27] A. Gimeno and M. L. Martins, "Micotoxicosis," in Enfermedades del Conejo (Tomo I, Generalidades), J. M. R. Pujol, Ed., pp. 439-464, Mundi-Prensa libros, Madrid, Spain, 2000.

[28] E. M. Binder, L. M. Tan, L. J. Chin, J. Handl, and J. Richard, "Worldwide occurrence of mycotoxins in commodities, feeds and feed ingredients," Animal Feed Science and Technology, vol. 137, no. 3-4, pp. 265-282, 2007.

[29] A. Dalcero, C. Magnoli, C. Hallak, S. M. Chiacchiera, G. Palacio, and C. A. R. Rosa, "Detection of ochratoxin A in animal feeds and capacity to produce this mycotoxin by Aspergillus section Nigri in Argentina," Food Additives and Contaminants, vol. 19, no. 11, pp. 1065-1072, 2002.

[30] T. Mohanamba, M. R. Rao, and S. M. M. Habibi, "Aflatoxin contamination in animal feeds," Indian Veterinary Journal, vol. 84, no. 4, p. 416, 2007.

[31] A. M. Shareef, "Moulds and mycotoxins in poultry feeds from farms of potential mycotoxicosis," Iraqi Journal of Veterinary Sciences, vol. 24, no. 1, pp. 17-25, 2010. 

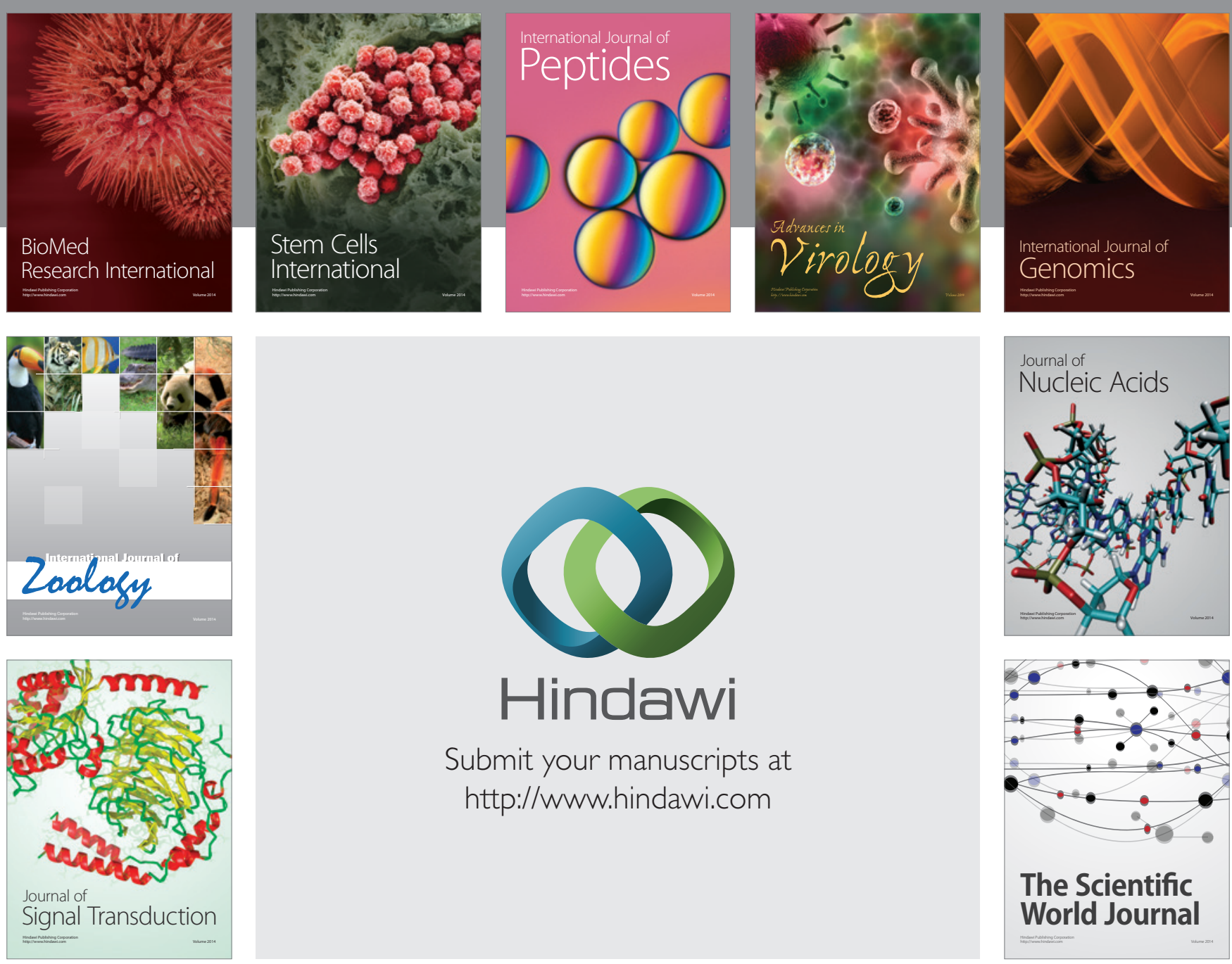

Submit your manuscripts at

http://www.hindawi.com
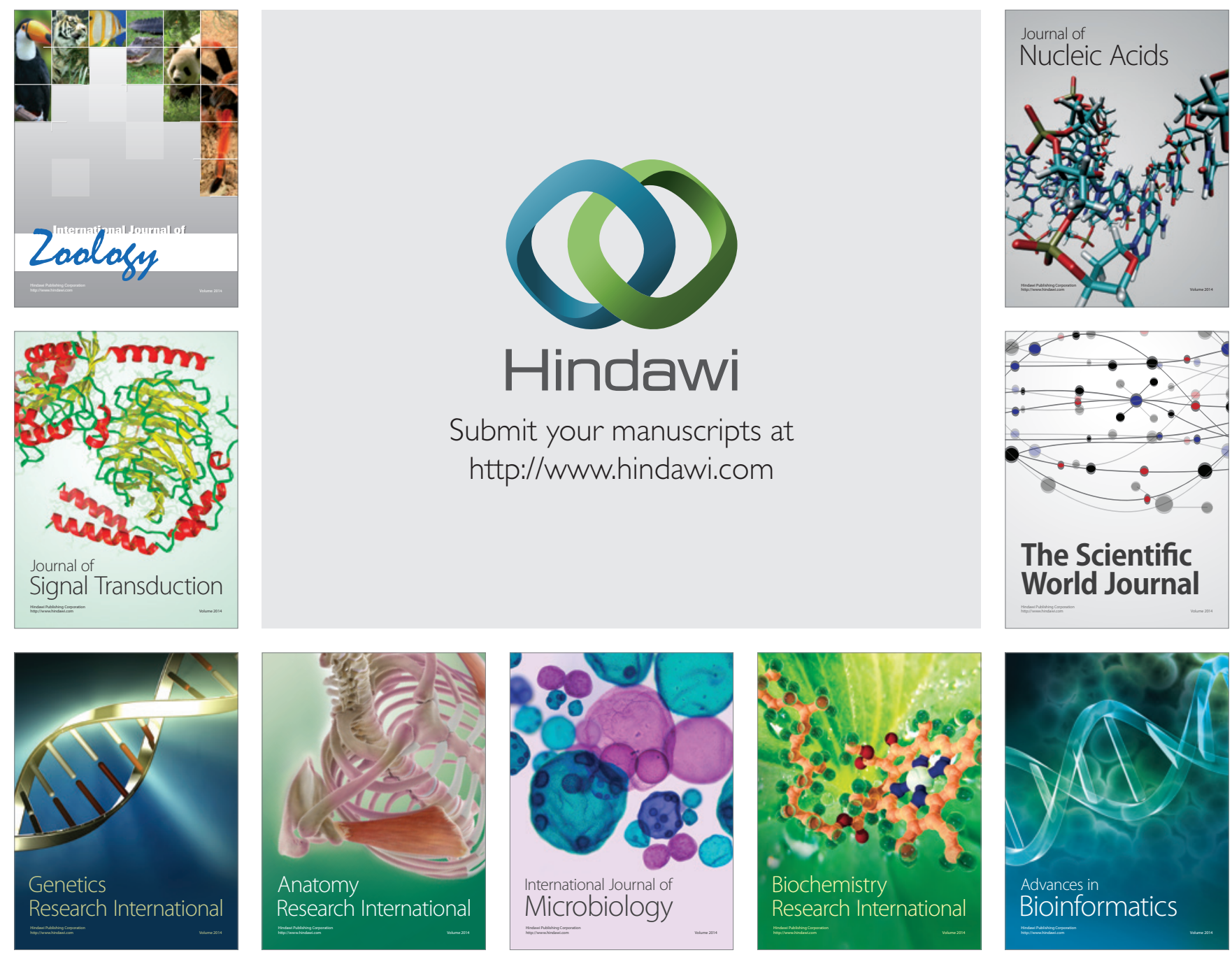

The Scientific World Journal
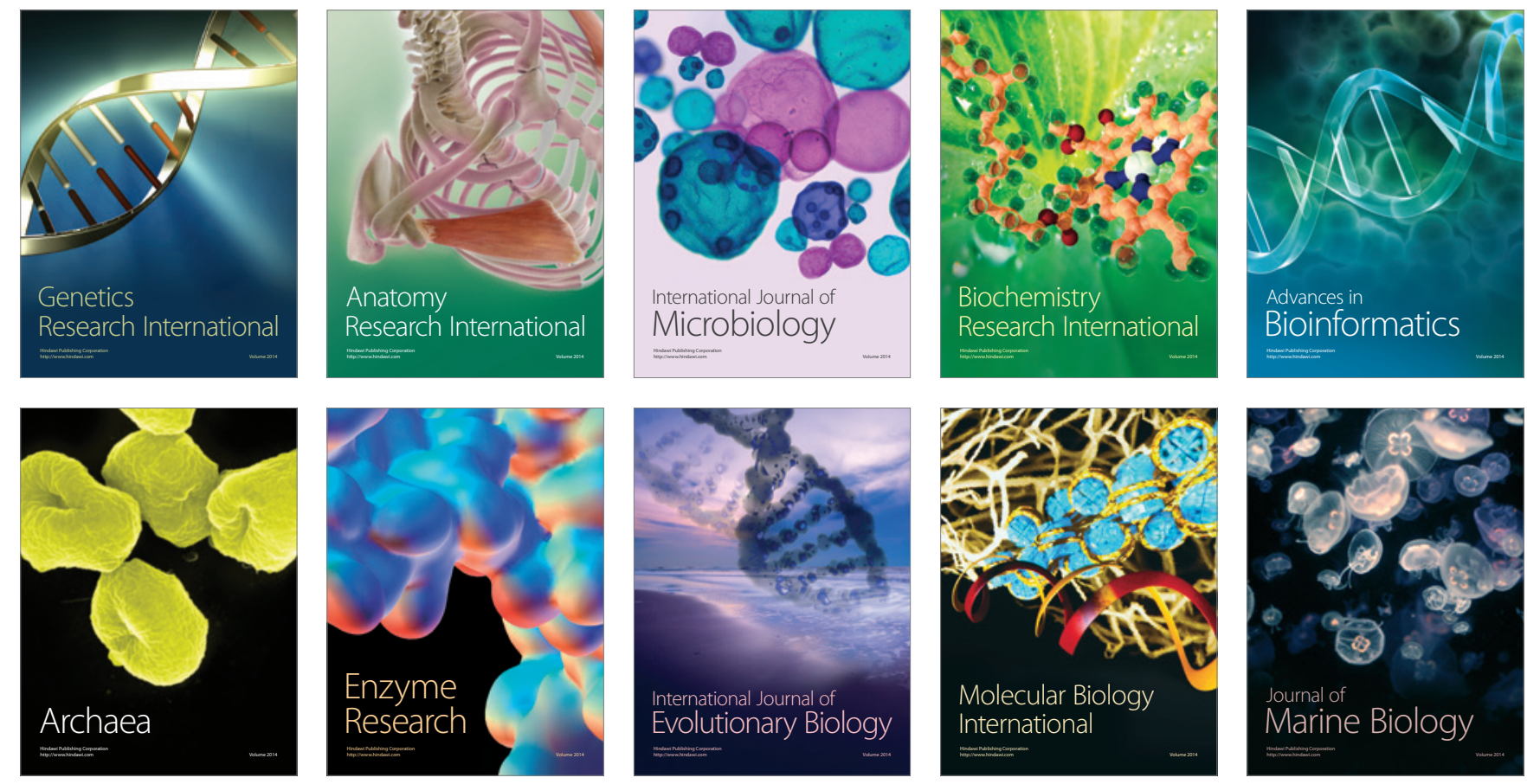